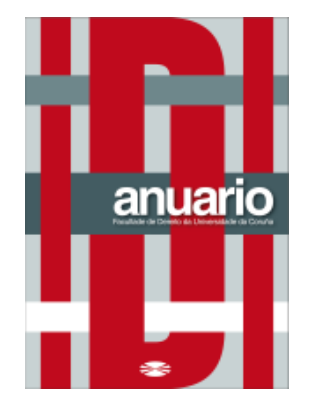

Anuario da Facultade de Dereito da Universidade da Coruña

Vol. 25 (2021), pp. 50-71

ISSNe: 2530-6324 || ISSN: 1138-039X

DOI: https://doi.org/10.17979/afdudc.2021.25.0.8798

\title{
LA MUERTE DE LUCRECIA: UNA DECISIÓN DE ÍNDOLE FAMILIAR
}

\section{LUCRECIA'S DEATH: A FAMILY-BASED DECISION}

\author{
MIGUEL HERRERO MEDINA \\ Profesor Ayudante Doctor \\ Departamento de Derecho Romano e Historia del Derecho \\ Universidad Complutense de Madrid \\ https://orcid.org/0000-0002-8749-4394
}

Recibido: $18 / 05 / 2021$

Aceptado: 23/09/2021

\begin{abstract}
Resumen: En los diferentes relatos que se han conservado sobre la muerte de Lucrecia se alude, de manera más o menos expresa, a la intervención de un consilium domesticum en los últimos compases de su vida. En este trabajo se realiza un análisis del contenido de las tres narraciones más pormenorizadas de este episodio histórico con el propósito de aclarar si esta institución doméstica estuvo involucrada de alguna forma en su muerte $\mathrm{y}$, en ese caso, arrojar algo de luz acerca de las posibles causas que habrían motivado una intervención de su comunidad familiar en este caso.
\end{abstract}

Palabras clave: Lucrecia, consilium domesticum, adulterio, antigua Roma

Abstract: On the written proof that has been preserved about Lucrecia's death, the consilium domesticum is inferred in several ways along the last moments of her life. This study analyses the content of the 3 most detailed accounts of this historical event with the purpose of clarifying if this domestic institution was somehow involved in her death and, in that case, shed some light on the possible reasons which might have prompted an intervention of her family community.

Keywords: Lucretia, consilium domesticum, adultery, Ancient Rome 
Sumario: I. LOS PRIMEROS VESTIGIOS DE UN CONSILIUM DOMESTICUM. II. EL RELATO DE LIVIO: UNA TRAGEDIA EN TRES ACTOS. 1 Primer acto: el virtuosismo de Lucrecia. 2. Segundo acto: la depravada conducta de Sexto Tarquinio. 3. Tercer acto: la muerte de Lucrecia. III. RELATO DE DIONISIO DE HALICARNASO: UN TESTIMONIO ALTERNATIVO. IV. SOBRE LA SANCIÓN DEL ADULTERIO EN LA ÉPOCA ANTIGUA. V. A MODO DE CONCLUSIÓN. BIBLIOGRAFÍA.

\section{LOS PRIMEROS VESTIGIOS DE UN CONSILIUM DOMESTICUM}

El hecho de que en las fuentes romanas aparezcan con frecuencia expresiones tales como "propinquorum et amicorum consilium", "consilium necessariorum" 2 , "amicorum consilium", "adhibere in consilium" o "in consilium advocare" 5 ha llevado a que tradicionalmente se haya venido aceptando la existencia de una especie de consejo de carácter doméstico que se habría encargado de intervenir en aquellos supuestos en los que algún miembro de una comunidad familiar se hubiera visto envuelto en hechos que despertasen una especial repercusión social y, por lo tanto, se requiriese del parecer de los componentes más destacados del grupo doméstico para determinar qué posición debía adoptar la comunidad ante esas situaciones.

De esa forma, cuando el pater familias tenía constancia de algún acontecimiento de estas características convocaba a los principales parientes, amigos y allegados de la familia para que escuchasen las explicaciones del miembro que se había visto afectado, evaluasen la situación en su conjunto y le ayudasen a emitir un veredicto a ese respecto. Atendiendo a esa funcionalidad, no es de extrañar que en muchas fuentes de naturaleza esencialmente literaria se empleasen términos jurisdiccionales para hacer referencia a diversas actuaciones que se llevaban a cabo en el seno de estos consejos domésticos, aludiendo especialmente a la figura del pater familias ${ }^{6}$, y que, de hecho, algunos autores hicieran alusión a la existencia de un pretendido "iudicium domesticum"?.

\footnotetext{
${ }^{1}$ Cfr. Val. Max., fact. et dict. mem. 5.8.2.

${ }^{2}$ Cfr. Val. Max., fact. et dict. mem. 5.8.3; 6.1.1.

${ }^{3}$ Cfr. Val. Max., fact. et dict. mem. 2.9.2.

${ }^{4}$ Cfr. Val. Max., fact. et dict. mem. 5.9.1.

${ }^{5}$ Cfr. Seneca, clem. 1.15.2.

${ }^{6}$ El pater familias aparece calificado en las fuentes como "disceptator domesticus" (Cic., pro Caec. 2.6), "domestici magistrati" (Sen., De benef. 3.11.2), "iudex domesticus" (Sen., contr. 2.3.18) o "censor suus" (Suet., Claud. 16), sobre las que E. VOLTERRA, «Il pretteso tribunale domestico in diritto romano», en $R I S G, 85,1948$, p. 32 afirmaba que "se si leggono senza presupposti le fonti, si può fácilmente constatare che nessuna di ese dimostra l'esistenza di questo pretese potere giurisdizionale".

${ }^{7}$ Esta expresión se contempla en hasta tres fragmentos procedentes de obras de Livio: "Ceterum sive illud domesticum sive publicum fuit iudicium, damnatur Servio Cornelio Q. Fabio consulibus" (Liv. 2.41.10), Cicerón: "Ad horum omnium iudicia tot atque tanta domesticum iudicium accessit sententiae damnationis tuae" (Cic., in Pis. 40.97) y Tertuliano: (...) "domesticis iudiciis nimis operata infestatio sectae huius obstruit defensioni" (Tertull., apol. 1.1).
} 
No obstante, esa terminología procesalista no debe inducir a pensar que estos consejos domésticos habrían llegado a constituir una verdadera jurisdicción doméstica ${ }^{8}$. Aunque se trata de una cuestión que ha suscitado un prolongado debate en la doctrina ${ }^{9}$, lo cierto es que, a la vista de las aportaciones realizadas principalmente por Volterra ${ }^{10}$, no parece que la resolución de conflictos en un consilium domesticum pudiera equipararse, bajo ningún concepto, a las controversias jurídicas que debían dirimirse en un proceso perfectamente reglamentado ante la jurisdicción pública romana.

En este sentido, únicamente podría contemplarse una cierta contraposición entre la represión criminal impulsada por las autoridades públicas, en el sentido de que parece indiscutible que habría existido una intervención familiar para sancionar internamente, incluso pese a que al mismo tiempo se sustanciase un proceso público, a los miembros de la familia inmersos en alguna controversia con gran repercusión social. No se trataría, por tanto, de una institución de carácter jurisdiccional, sino que se ajustaría más bien a las características de un consejo consultivo ${ }^{11}$, que se habría desenvuelto en el contexto del ejercicio de la patria potestas reconocida al pater familias.

Se trataba de un mecanismo de protección de la familia, o más concretamente, de protección de la reputación familiar. La aplicación de sanciones especialmente duras a los miembros del grupo doméstico que habían vulnerado las normas de comportamiento social buscaba trazar una línea de separación entre la conducta de la persona que había sido condenada por el consilium domesticum y el resto de la familia. Con estas decisiones el pater familias no solo reafirmaba su autoridad en el seno de la comunidad familiar, sino que además se anticipaba a una eventual condena pública del miembro de su grupo, evitaba cualquier tipo de represalias por parte de los sujetos

\footnotetext{
${ }^{8}$ Sobre esta cuestión, cabe destacar el testimonio de A. BALDUCCI, «Intorno al iudicium domesticum», en Archivio Giuridico Filippo Serafini, 191, 1976, p. 90, afirmando que "quando la letteratura tradizionale parla di giurisdizione familiare del pater, intende dire che questi svolge una attività «giudiziaria», attua un iudicium, che sono analoghi (non identici) a quelli che svolgono a Roma organi statuali per l'accertamento di fatti e responsabilità e per condanne di natura penale".

9 A este respecto resultan especialmente ilustrativas las palabras de N. DONADIO, «Iudicium domesticum, riprovazione sociale e persecuzione publica di atti commessi da sottoposti alla patria potestas», en Index, 40, 2012, p. 175 cuando comienza señalando que "la maggior parte degli studiosi riconosce la storicità di un tribunale domestico, per giudicare i sottoposti alla patria potestas, e lo considera espressione di una vera e propria giurisdizione esercitata dal capo del grupo familiare sui suoi soggetti". Dentro del sector doctrinal que defiende la existencia de un consilium domesticum con funciones jurisdiccionales se encuentran autores como P. BONFANTE, Corso di diritto romano I, Roma, 1925, p. 74 ss.; R. DÜLL, «Iudicium domesticum, abdicatio und apokeryxis», en ZSS, 63, 1943, p. 57 ss.; W. KUNKEL, «Das Konsilium im Hausgericht» en ZSS, 83, 1966, p. 219 ss.; A RUGGIERO, «Nuove riflessioni in tema di tribunale domestico», en Sodalitas. Scritti in onore di A. Guarino, 4, 1984, p. 1953 ss.; C. RUSSO RUGGERI, «Ancora in tema di iudicium domesticum», en Iuris Antiqui Historia, 2010, pp. 52 ss.

${ }^{10}$ Pese a que el principal exponente de esta teoría fuese E. VOLTERRA, Il pretteso tribunale domestico, op. cit., p. 103 ss., el propio romanista italiano advierte en su obra de que anteriormente T. MOMMSEN, Römisches Strafrecht, Leipzig, 1899, p. 17 nt. 1, ya había puesto de manifiesto que no existía una verdadera jurisdicción doméstica en la antigua Roma. En esta misma línea también se pronuncian G. DE SANCTIS, Storia dei Romani, vol. IV.2, Florencia, 1958, p. 40; E. POLAY, «Das "regimen morum" des Zensors und die sogenannte Hausgerichtsbarkeit», en Studi in onore di Edoardo Volterra III, Milán, 1971, p. 263 ss.; M. KASER, Das römische Privatrecht, vol. I, Múnich, 1971, p. 63.

${ }^{11}$ Siguiendo ese mismo orden de ideas, G. WESENER, «Iudicium domesticum», en Realenzyklopädie der klassischen Altertumwissenschaft, Suppl. 9, 1962., p. 374, afirmaba que: "Das consilium hat aber nur eine beratende funktion; die Entscheidung liegt beim pater familias und beruht auf dessen potestas".
} 
ofendidos $\mathrm{y}$, sobre todo, ratificaba su más firme adhesión a los estándares de comportamiento que socialmente imperaban en la antigua sociedad romana ${ }^{12}$.

Aunque la institución del consilium domesticum aparece recogida en episodios acaecidos en diversas épocas históricas, todo parece apuntar a que su origen se remonta a los primeros compases de la historia jurídica romana ${ }^{13}$. La referencia más antigua que se conserva en relación con la posible existencia del consilium domesticum en la antigua sociedad romana procede de un fragmento de la obra de Valerio Máximo en el que se rememoran las circunstancias que habrían rodeado la violación padecida por Lucrecia a manos de Sexto Tarquinio y su posterior suicidio. A este respecto, se recuerda que, antes de quitarse la vida, la joven habría procedido a describir la ofensa que había sufrido en sus propias carnes ante sus familiares y allegados, en lo que el autor no duda en calificar como un "concilium necessarium".

Val. Max., fact. et dict. mem. 6.1.1: Dux Romanae pudicitiae Lucretia, cuius uirilis animus maligno errore fortunae muliebre corpus sortitus est, a $<$ Sex. $>$ Tarquinio regis Superbi filio per uim stuprum pati coacta, cum grauissimis uerbis iniuriam suam in concilio necessariorum deplorasset, ferro se, quod ueste tectum adtulerat, interemit causamque tam animoso interitu imperium consulare pro regio permutandi populo Romano praebuit.

Como se puede observar, este fragmento no contempla un relato pormenorizado de la historia de Lucrecia, sino que Valerio Maximo se habría limitado a reproducir de manera muy sintética unos hechos que estaban arraigados en la conciencia colectiva de los romanos desde mucho tiempo atrás, pues se contemplaban en fuentes de todo tipo ${ }^{14}$. Ahora bien, este testimonio también resulta fundamental a nuestros efectos porque sería la primera vez que se aludiría en las fuentes a la presencia de un "consilium domesticum" en los últimos compases de la vida de Lucrecia.

Sin embargo, ante la imposibilidad de obtener más información sobre este punto a partir de este fragmento, no nos queda más remedio que acudir a los relatos de otros autores anteriores en el tiempo que, si bien es cierto que mantienen una gran distancia temporal con los acontecimientos referidos en relación con el fallecimiento de Lucrecia, se ocuparon de este episodio legendario con mucho más detenimiento. A lo

\footnotetext{
12 En esa misma línea, G. GROSSO, «L'esame di coscienza di uno storico e i problema del più antico sviluppo costituzionale romano», en $\operatorname{RISG}, 2,1948$, p. 125, señala que el consilium domesticum se habría mantenido vigente en el tiempo por varios motivos: "da un lato il desiderio del pater di sottrarre il filius alla umiliazione della pena pubblica e anche, di mostrare il proprio lealismo verso la civitas; dall'altro, in quest'ultima, lo scarso interesse di diminuire un'autorità, che si esplicava anche in suo favore. In età storica la giustizia paterna si esercita con le più gravi sanzioni in casi ove lo Stato stesso potrebbe intervenire: si ha quindi una inteligente applicazione di un istituo arcaico".

${ }^{13}$ Un compendio de los casos en que se alude a una posible intervención de este "consilium domesticum" puede encontrarse en C. FAYER, La familia romana, vol. I, Roma, 1994, p. 130 ss.

14 El episodio protagonizado por la joven Lucrecia aparece mencionado, con mayor o menor detenimiento, en varias obras de Cicerón (Cic., de rep. 2.25.46; de fin. 2.20.66; 5.22.64; de leg. 2.4.10), Livio (Liv. 1.57) Dionisio de Halicarnaso (Dion. Hal., Ant. Rom. 4.64 ss.), Diódoro Sículo (Diod., exc. Vales. P. 558), Ovidio (Ovid., Fasti 2.721 ss.), Lucio Anneo Floro (Florus 1.7.11); Dión Casio (Dion. Cass., fr. 11.13 ss.), Servio (Serv., Aen. 6.819; 8.646); Aurelio Víctor (Aur. Vict., de vir. ill. 9); Lido (Lyd., de mensibus 4.24); Zonaras (Zon. 7.11); Tertuliano (Tertull., de exhort cast. 13; de monog. 17; ad Martyr. 4) y en la mitografía vaticana (Mytogr. Vat. vol. I fab. 74). Este elenco de fuentes ha sido tomado de E. VOLTERRA, Il pretteso tribunale domestico, op. cit., p. $125 \mathrm{nt}$. 44, quien a su vez remite a la obra de A. SCHWEGLER, Römische Geschichte, vol. I.2, Tubinga, 1853, p. 766 ss.
} 
largo de los siguientes apartados vamos a intentar arrojar algo de luz, siempre partiendo del análisis exegético de las fuentes, en torno a la que podría haber sido la primera intervención que se conserva del consilium domesticum en la historia jurídica romana.

\section{EL RELATO DE LIVIO: UNA TRAGEDIA EN TRES ACTOS}

Como hemos señalado en el apartado anterior, el mito de la muerte de Lucrecia constituyó uno de los relatos legendarios más difundidos en la antigua sociedad romana, pues no solo habría servido para poner de manifiesto el virtuosismo de una joven que habría decidido anteponer la honorabilidad de su comunidad familiar a su propia vida, sino que además habría constituido un hito en el devenir de la historia política romana para dar a entender los motivos que habrían propiciado el declive de la monarquía romana y la consiguiente instauración del régimen republicano a finales del siglo VI a.C. ${ }^{15}$.

De esta forma se explica que tantos autores de épocas tan distantes en el tiempo se hicieran eco de este episodio en sus obras. Ahora bien, cabe destacar que los relatos más pormenorizados que se han conservado sobre la historia de Lucrecia proceden en su mayoría de obras del siglo I a.C. con una marcada pulsión instructiva. Se trata de obras que se encuadrarían en el contexto de los intentos de reconversión moral de la sociedad romana que fueron impulsados inicialmente durante el mandato de Octavio Augusto y que posteriormente habrían sido continuados por Tiberio ${ }^{16}$.

Las aportaciones realizadas por autores como Livio, Dionisio de Halicarnaso o Valerio Máximo a esta política habrían consistido en recoger una exposición de relatos ejemplificadores en los que se exaltaran aquellos comportamientos virtuosos que debían imitarse por parte de sus contemporáneos $\mathrm{y}$, al mismo tiempo, poner de manifiesto otras actitudes abyectas que, por el contrario, debían ser rechazadas. Aunque parece que estos autores beben de una misma fuente en común, que posiblemente fuese Fabio Pictor ${ }^{17}$, lo cierto es que sus testimonios presentan notables divergencias en relación con la posible presencia de un consilium domesticum en la muerte de Lucrecia.

El testimonio más completo sobre este famoso episodio histórico se encuentra contemplado en ad urbe cond. 1.57 ss. de Livio, que no solo contiene la narración más minuciosa de los hechos acaecidos, sino que además puede considerarse como la versión oficial del mito de Lucrecia extendida en la antigua Roma y, precisamente por

\footnotetext{
15 Aunque la doctrina moderna se muestra prácticamente unánime a la hora de considerar que este episodio no habría podido propiciar por sí mismo la caída del régimen monárquico romano. Sobre esta cuestión, vid. F. DE MARTINO, Storia della Costituzione romana, vol. I, Jovene, Nápoles, 1972, p. 224. ${ }^{16}$ En este sentido, F. RÖMER, «Zum Aufbau der Exemplasammlung des Valerius Maximus», en WS 103, 1990, p. 99 ss. destacó en su momento que la obra de Valerio Máximo estaba principalmente encaminada, con un evidente ánimo de reconversión moralista, a las élites romanas de su época. Sobre la ejemplaridad en la obra de Valerio Máximo, vid. G. MALASKOV, «Valerius Maximus and Roman Historiography. A Study of the exempla Tradition», en $A N R W$ II, 32 (1), pp. 437-496.

${ }^{17}$ Se trata de una hipótesis, apuntada en su día por C. APPLETON, «Trois épisodes de l'histoire ancienne de Rome: les Sabines, Lucrèce, Virginie», en $R H, 4.3,1924$, p. 193 ss., fundamentada en las dos alusiones que se recogen a este historiador romano en el relato que Dionisio de Halicarnaso realiza sobre la muerte de la joven Lucrecia (Dion. Hal., Hist. Rom. 4.64.3).
} 
ese motivo, es posible que fuese una de las principales referencias textuales de las que se habría valido Valerio Máximo para documentar su relato sobre la joven Lucrecia ${ }^{18}$.

Una somera aproximación a la obra de Tito Livio permite distinguir una división interna del relato en tres grandes $\operatorname{actos}^{19}$ : en el primero se alude a los prolegómenos que anteceden a la violación de Lucrecia, aprovechando esta circunstancia para presentar a cada uno de los personajes que protagonizan este episodio histórico, para a continuación centrarse en la agresión sexual sufrida por la joven y, por último, acabar rememorando las gravísimas consecuencias que estos sucesos habrían acarreado tanto para Lucrecia como para el devenir histórico de la monarquía romana.

Respetando esa división narrativa, a lo largo de los siguientes epígrafes vamos a repasar de una forma más detenida cada uno de los acontecimientos relatados en la obra de Tito Livio con el fin de aclarar, en la medida de lo posible, hasta qué punto se puede hablar como tal de la intervención de un consilium domesticum en la muerte de Lucrecia y, en ese caso, por qué motivos habría intervenido en esta situación.

\section{II.1. PRIMER ACTO: EL VIRTUOSISMO DE LUCRECIA}

El primero de estos actos comienza situando la acción en el campamento romano que asediaba la ciudad de Ardea en el contexto de las campañas bélicas emprendidas por el rey Tarquinio el Soberbio contra los rútulos. En estas situaciones era muy habitual, explica Livio, que los oficiales romanos celebrasen fiestas para pasar el tiempo mientras se mantenían sitiadas las posiciones enemigas ${ }^{20}$. Y precisamente en una de esas fiestas celebradas por Sexto Tarquinio, hijo del rey, se habría generado una discusión en torno al virtuosismo de las esposas de los oficiales presentes.

Según fue aumentando el cariz de la discusión, uno de los asistentes a la fiesta llamado Colatino ${ }^{21}$ habría propuesto que la única forma de dar solución a esa controversia pasaba porque todos los presentes regresasen en grupo a sus hogares para comprobar en que menesteres andaban ocupadas sus esposas. El resultado de estas comprobaciones no habría podido resultar más dispar, pues mientras que la mayoría de las mujeres, entre las que se contaban las nueras del monarca, habían sido sorprendidas en medio de diversas celebraciones, rodeadas de toda clase de suntuosidades y en compañía de otros hombres, cuando la comitiva llegó a la casa de Colatino habrían encontrado a su esposa Lucrecia entregada a la realización de sus quehaceres domésticos.

\footnotetext{
${ }^{18}$ Se trata de una idea apuntada por E. VOLTERRA, Il preteso tribunale domestico, op. cit., p. 125 nt. 45 , quien remite a las obras de varios autores del siglo XIX para analizar con mayor profundidad las fuentes en las que se habría basado Valerio Máximo para escribir su obra.

19 En este punto nos vamos a ajustar a la ordenación realizada por A. GUARINO, «Il dossier di Lucrezia», en Labeo 5, 1959, pp. 211-213, en la que divide "la stupenda e concisa narrazione di Livio" en tres actos consecutivos perfectamente diferenciados en el tiempo.

${ }^{20}$ Cfr. Livio 1.57

21 Acerca de Lucio Cornelio Colatino, T. P. WISEMAN, «Roman Republic, year one», en Greece \& Rome, 45.1, 1998, p. 20 ha destacado qué si bien es cierto que estaba emparentado con la gens de los Tarquinios, pues era sobrino de Tarquinio Prisco, no habría compartido los vicios de los que adolecían sus miembros. Para conocer más acerca de la vida de este personaje histórico, vid. s.v. «Tarquinius Collatinus, Lucius», en The Oxford Classical Dictionary, Nueva York, 1970, p. 1039.
} 
Concretamente Livio recuerda que la joven se encontraba tejiendo en compañía de sus criadas, actividad que, como es bien sabido, constituye una de las tareas domésticas que se emplea con frecuencia en las fuentes antiguas a la hora de reflejar el virtuosismo de una buena matrona romana ${ }^{22}$. Y no solo eso, sino que, además, Livio afirma que acogió con gran satisfacción la llegada de su esposo y sus acompañantes. Ante esa demostración de integridad en su conducta, todos los presentes habrían coincidido en que Lucrecia era, sin lugar a dudas, la mujer más virtuosa de Roma.

Sin embargo, esta constatación habría generado otras inesperadas consecuencias, pues como colofón a ese primer acto, Livio destaca que el ejemplar comportamiento de la joven Lucrecia habría obnubilado a Sexto Tarquinio, quien a partir de ese momento habría comenzado a cavilar un plan para conquistarla.

Liv. 1.57: Tarquinium mala libido Lucretiae per vim stuprandae capit; cum forma tum spectata castitas incitat. Et tum quidem ab nocturno iuvenali ludo in castra redeunt.

A través de esta introducción, Livio presenta a los dos principales protagonistas de la trama que se desarrollará en los siguientes actos, destacando sus rasgos distintivos $\mathrm{y}$, sobre todo, incidiendo con claridad en la contraposición entre la depravada conducta de Sexto Tarquinio, apuntada ya anteriormente por Livio en el episodio de los gabinios $^{23}$, y el reconocido virtuosismo de la joven Lucrecia. Una vez introducidos estos personajes, comienza propiamente el desarrollo del episodio en cuestión.

\section{II.2. SEGUNDO ACTO: LA DEPRAVADA CONDUCTA DE SEXTO TARQUINIO}

Con el recuerdo de la virtuosa condición de Lucrecia aún fresco en la memoria y siendo plenamente consciente de que Colatino se encontraba acantonado en Ardea, Sexto Tarquinio habría aprovechado que debía llevar a cabo unos encargos para regresar en compañía de un amigo a Colacia ${ }^{24}$. Allí habría sido recibido muy amablemente en

\footnotetext{
${ }^{22}$ El modelo ideal de matrona romana se resume en la máxima "casta fuit, domum seruauit, lanam fecit", localizado en el epitafio de la tumba de una mujer romana llamada Claudia (C.I.L. 1.1007 y 6.15.364). Sobre la posición de las mujeres en la antigua sociedad romana cabe destacar, con abundante bibliografía, a M. SALAZAR REVUELTA, «Estatus jurídico y social de la materfamilias en el marco de la ciudadanía romana», en Mulier: algunas historias e instituciones de Derecho Romano, Dykinson, 2013, p. 199 ss.

${ }^{23}$ Tito Livio recuerda que Sexto Tarquinio se habría presentado en la ciudad de Gabii haciéndose pasar por un refugiado que escapaba de la crueldad de su padre, insistiendo en que debía ser derrocado a toda costa, antes de que reiniciase una nueva guerra (Liv. 1.53). Los gabinios acogieron con hospitalidad a este joven, confiaron en sus palabras y paulatinamente le fueron otorgando mayores cuotas de poder, hasta el punto de que fue elegido como comandante de las tropas gabinias. Y habiendo alcanzado ese cargo, Sexto Tarquinio comenzó entonces una depuración de los grandes prohombres de Gabii para finalmente entregar esa ciudad a su padre sin necesidad de entrar siquiera en combate (Liv. 1.54). Aunque la doctrina romanística rechaza que este episodio hubiera pudido desarrollarse como lo cuenta Livio, que de acuerdo con R. M. OGILVIE, A Commentary on Livy. Books 1-5, Oxford, 1965, p. 205, simplemente recogió una narración contemplada en la obra de Heródoto (Herod. 3.1.25 y 5.92.6), no cabe duda de que la inclusión de este relato en la obra de Livio tendría como finalidad poner de manifiesto el malévolo carácter de Sexto Tarquinio. En relación con la posible relación política que se habría forjado entre Roma y Gabii, vid. S. MONTERO HERRERO, «Gabii a través del foedus gabinum», en Cuadernos de trabajos de la Escuela Española de Historia y Arqueología en Roma, 15, 1981, pp. 9-16.

${ }^{24}$ El término que Livio utiliza para referirse al acompañante de Sexto Tarquinio es "comes", que como ha señalado A. GUARINO, Il dossier di Lucrezia, op. cit., p. $212 \mathrm{nt}$. 10, pese a que es posible interpretar que
} 
casa de Lucrecia, quien, a pesar de no esperar esa visita, una vez más habría dado muestras de su hospitalidad ofreciendo alojamiento a tan ilustres huéspedes.

Liv. 1.58: Paucis interiectis diebus Sex. Tarquinius inscio Collatino cum comite uno Collatiam venit. Ubi exceptus benigne ab ignaris consilii cum post cenam in hospitale cubiculum deductus esset.

Con el propósito de apuntalar aún más si cabe el gran virtuosismo de Lucrecia, Livio recalca que la joven no podía sospechar nada acerca de los planes que maquinaba en esos momentos el hijo del rey ${ }^{25}$. Sin embargo, en cuanto cayó la noche, recuerda que este habría aprovechado que todos los habitantes de la casa se encontraban durmiendo para deslizarse de forma sigilosa hasta los aposentos de Lucrecia $\mathrm{y}$, blandiendo su espada, habría amenazado con matarla inmediatamente si pedía auxilio. Consciente de que tenía la situación bajo control, Sexto Tarquinio le habría confesado sus profundos sentimientos de amor a Lucrecia, rogando en primera instancia para que correspondiese a sus afectos y amenazándole después, para que accediera a sus deseos.

Liv. 1.58: (...) amore ardens, postquam satis tuta circa sopitique omnes videbantur, stricto gladio ad dormientem Lucretiam venit sinistraque manu mulieris pectore oppresso "Tace, Lucretia" inquit; "Sex. Tarquinius sum; ferrum in manu est; moriere, si emiseris vocem." Cum pavida ex somno mulier nullam opem, prope mortem imminentem videret, tum Tarquinius fateri amorem, orare, miscere precibus minas, versare in omnes partes muliebrem animum.

Pese a la insistencia del joven príncipe, Lucrecia se habría mantenido inflexible en su oposición a mantener relaciones sexuales. Al constatar que sus amenazas resultaban absolutamente infructuosas, pues la joven estaba dispuesta a morir antes que a acceder a sus pretensiones, Sexto Tarquinio habría cambiado su estrategia de intimidación con la apelación a una amenaza aún peor que la muerte. De acuerdo con el relato de Tito Livio, el hijo del rey habría explicado a Lucrecia que si persistía en su actitud no solo perdería su vida, sino que además sufriría la enorme deshonra de ser descubierta al día siguiente junto al cadáver de uno de sus criados, pues Sexto Tarquinio se encargaría de ejecutarlo y depositarlo en su cama, haciendo público posteriormente que había tomado la decisión de ejecutar a ambos amantes cuando los había descubierto cometiendo adulterio. Solo de esa manera, atemorizando a la joven con las graves consecuencias que se derivarían para su recuerdo, y que pesarían sobre su familia, a raíz de una muerte tan deshonrosa, habría conseguido doblegar la férrea voluntad de Lucrecia.

Liv. 1.58: Ubi obstinatam videbat et ne mortis quidem metu inclinari, addit ad metum dedecus: cum mortua iugulatum servum nudum positurum ait, ut in sordido adulterio necata dicatur. Quo terrore cum vicisset obstinatam pudicitiam velut vi victrix libido, profectusque inde Tarquinius ferox expugnato decore muliebri esset...

se trataba de un esclavo, lo cierto es que parece mucho más probable que "il comes di Sesto era un amico o un cliente, che gli fece scorta lungo il camino malfido da Ardea a Collatia".

${ }^{25}$ A través de la expresión "Ubi exceptus benigne ab ignaris consilii cum post cenam in hospitale cubiculum deductus esset” (Liv. 1.58), Livio pretendía recalcar aún más el legendario virtuosismo de Lucrecia, quien, como se espera de una buena anfitriona romana, ignorando las sórdidas maquinaciones de Sexto Tarquinio, acoge al hijo del monarca en su casa y le ofrece alojamiento para pasar la noche. 
De esta forma tan abrupta acaba el segundo acto de la trama. Se trata nuevamente de una determinación adoptada conscientemente por Livio con el propósito de preservar el virtuosismo de la joven Lucrecia ${ }^{26}$. En lugar de detenerse en relatar más detalles acerca de los sucesos acaecidos durante esa fatídica noche, el autor decide proseguir su relato adentrándose en las consecuencias que se habrían derivado de la violación de Lucrecia cuando tanto sus familiares como el pueblo romano conocen estos hechos.

\section{II.3. TERCER ACTO: LA MUERTE DE LUCRECIA}

A la mañana siguiente, destrozada por el ultraje sufrido, Lucrecia habría enviado sendos mensajeros tanto a su padre como a su marido para que, acompañados por algún amigo de confianza, acudieran hasta Colacia en su ayuda. De acuerdo con la narración de Livio, en poco tiempo habrían llegado a Colacia tanto su padre Espurio Lucrecio $^{27}$, junto con su amigo Publio Valerio ${ }^{28}$, como su marido Colatino, que venía acompañado de Lucio Junio Bruto ${ }^{29}$, en ese momento tribunus celerum de Roma, a quien se habría encontrado en el camino cuando atendía al mensajero enviado desde Colacia.

Liv. 1.58: Lucretia maesta tanto malo nuntium Romam eundem ad patrem Ardeamque ad virum mittit, ut cum singulis fidelibus amicis veniant; ita facto maturatoque opus esse; rem atrocem incidisse. Sp. Lucretius cum P. Valerio Volesi filio, Collatinus cum L. Iunio Bruto venit, cum quo forte Romam rediens ab nuntio uxoris erat conventus.

Al encontrar a Lucrecia sumida en un mar de lágrimas, le rogaron que explicase los motivos de su aflicción. Y entonces la joven habría relatado los acontecimientos que habían tenido lugar durante la noche anterior, denunciando la agresión sufrida a manos del hijo del monarca y rogando a su padre, su marido y sus acompañantes que tomasen cartas en este asunto para que esos hechos no quedasen

\footnotetext{
${ }^{26}$ M. J. BRAVO BOSCH, «El iudicium domesticum», en Revista General de Derecho Romano, 17, 2011, pp. 88-89 ha puesto de manifiesto que en esta parte del relato Livio "de nuestra protagonista no dice nada, no explica su expresión al verse acorralada, si Sexto arremetió con más violencia - si cabe - contra ella, ni tampoco describe el dormitorio donde dormía, en un afán claro de respetar la conciencia incólume de Lucrecia, que pierde su pudor físicamente pero no espiritualmente, y que debe ser tratada con la mayor delicadeza a la hora de referirse a ella y al gravísimo momento de la violación. Es por ello que se habla del delito cometido, pero con una exquisitez oratoria que busca respetar al máximo a Lucrecia en su dolor".

${ }^{27}$ A tenor de la escasa información conservada, tenemos constancia de que el padre de Lucrecia portaba el cognomen Triciptinus, lo que indicaría su pertenencia a la gens Lucretia, y que habría ocupado el cargo de prefecto urbano en los últimos compases del reinado de Tarquinio el Soberbio (Liv. 1.59).

${ }^{28}$ Publio Valerio Publícola fue un destacado miembro de la gens Valeria que habría pasado a la historia como uno de los fundadores de la república romana, ya que poco después de la caída de la monarquía pasó a ocupar el cargo de cónsul en sustitución de Colatino (Liv. 2.2). Durante su mandato redujo el número de fasces romanas a la mitad, estableció que cualquier ciudadano podía dar muerte a quien pretendiese erigirse como nuevo rey de Roma y reconoció la posibilidad de apelar al pueblo (provocatio ad populum) para que se pronunciase sobre la posible aplicación de la pena capital impuesta por un magistrado a un ciudadano. Sobre la biografía de este personaje, cfr. Plut., Vidas Paralelas, vol. I. Publícola.

${ }^{29}$ Lucio Junio Bruto es uno de los personajes más conocidos de la historia romana gracias a su actuación en el derrocamiento de su tío Tarquinio el Soberbio y la consiguiente edificación de la república romana, en la que ostentó el primer consulado junto a Colatino (Liv. 1.56-60).
} 
impunes ${ }^{30}$. Después de escuchar su relato, todos ellos se comprometieron a vengar ese ultraje y trataron de convencer a la joven de que no había cometido ninguna actuación reprochable en virtud a la máxima de que "mentem peccare, non corpus" (Liv. 1.58).

Sin embargo, esas palabras no surtieron efecto en Lucrecia, que ya había tomado una determinación sobre su destino. Una vez obtenido el compromiso de que vengarían la ofensa que había sufrido, habría afirmado que si bien podía quedar libre de cualquier culpabilidad, no podía eximirse de la pena, pues no quería que ninguna mujer pudiera alegar el ejemplo de Lucrecia en el futuro ${ }^{31} \mathrm{y}$, por eso, a continuación se habría quitado la vida con un puñal que portaba entre sus ropas.

Liv. 1.58: Cultrum, quem sub veste abditum habebat, eum in corde defigit, prolapsaque in volnus moribunda cecidit. Conclamat vir paterque.

Este fatal desenlace habría propiciado que los presentes, espoleados por la cólera de Lucio Junio Bruto, incitasen a la población de Colacia a levantarse en armas contra los abusos cometidos por los Tarquinios. Acompañados por una gran multitud armada se desplazaron hasta el foro de Roma, donde Bruto pronunció un discurso denunciando los abusos cometidos por los distintos miembros de la familia real ${ }^{32}$, incitando al pueblo a rebelarse contra Tarquinio el Soberbio ${ }^{33}$. Con el apoyo del ejército instalado en Arpea, los sublevados habrían despojado de soberanía a todos los miembros de la familia real, que no habrían tenido más remedio que marchar al exilio, dando de esta manera paso a la instauración del nuevo régimen republicano.

\section{RELATO DE DIONISIO DE HALICARNASO: UN TESTIMONIO ALTERNATIVO}

Más allá de la posible verosimilitud de este relato legendario, que evidentemente adolece de una verdadera consistencia histórica ${ }^{34}$, nuestra atención debe

\footnotetext{
${ }^{30}$ G. RIZELLI, «In has servandae integritatis custodias nulla libido inrumpet (Sen., contr. 2.7.3). Donne, passioni, violenza», en Violenza sessuale e società antiche. Profili storico-giuridici, p. 154 nt. 11 ha destacado que "la donna appare agli antichi autori particularmente incline allá vendetta".

${ }^{31}$ Se trata de la famosa frase pronunciada por Lucrecia: "Vos" inquit "uideritis quid illi debeatur: ego me etsi peccato absolvo, supplicio non libero; nec ulla deinde impudica Lucretiae exemplo vivet" (Liv. 1.58), que como señala E. CANTARELLA, Dammi mille baci. Veri uomini e vere donne nell'antica Roma, Milán, 2016, p. 46: "le donne romane sono avvertite: cosí debe fare una moglie, se il suo corpo - anche contro la sua volontà - è appartenuto a un altro uomo. Un esemplo tra i più celebri e amati dai romani”.

${ }^{32}$ Liv. 1.59: Brutus illis luctu occupatis cultrum ex volnere Lucretiae extractum, manantem cruore prae se tenens, "Per hunc" inquit "castissimum ante regiam iniuriam sanguinem iuro, vosque, di, testes facio me L. Tarquinium Superbum cum scelerata coniuge et omni liberorum stirpe ferro igni quacumque dehinc vi possim exsecuturum, nec illos nec alium quemquam regnare Romae passurum. "Cultrum deinde Collatino tradit, inde Lucretio ac Valerio, stupentibus miraculo rei, unde novum in Bruti pectore ingenium. Ut praeceptum erat iurant; totique ab luctu versi in iram, Brutum iam inde ad expugnandum regnum vocantem sequuntur ducem.

${ }^{33}$ Esa conducta ha llevado a que una buena parte de la doctrina moderna considere que desde el primer momento la intervención de Bruto en todos estos hechos estuviera encaminada a alcanzar el poder en Roma. Sobre esta cuestión, vid. V. GROH, «La cacciata dei re romani. Analisi letteraria e storica», en Athenaeum, 6, 1928, p. 289 ss.; A. MASTROCINQUE, «La cacciata di Tarquinio il Superbo: tradizione romana e letteratura greca», en Athenaeum, 62, 1984, p. 229 ss.; C. L. BANKSTON, «Marcus Junius Brutus», en Great Lives from History: Notorious Lives, Salem Press, 2007, pp. 146-148; Y. LE BOHEC, M. LE GLAY y J. L. VOISIN, A History of Rome, Wiley-Blackwell, 2009.

${ }^{34}$ I. DONALDSON, The Rapes of Lucretia: A Mith and its Transformations, Nueva York, 1982, p. 6 ss. ha señalado que la doctrina se divide entre aquellos que afirman que se trata de un episodio ficticio
} 
concentrarse en analizar la posible intervención de un "consilium domesticum" en los prolegómenos que anteceden a la muerte de la joven Lucrecia, pues si bien es cierto que Valerio Máximo parece confirmar este extremo, sin embargo, en el relato que hemos comentado de Livio no se aprecia con claridad que efectivamente actuase un consejo de estas características. Por ese motivo, resulta indispensable ocuparse de un tercer relato conservado acerca de la muerte de Lucrecia para arrojar algo de luz sobre este episodio histórico.

Se trata de un testimonio recogido en la obra de Dionisio de Halicarnaso donde también se toma como punto de partida la campaña militar dirigida por el rey Tarquinio el Soberbio contra los ardeates ${ }^{35}$. En cuanto que se trataba de un destacado miembro del ejército romano, Sexto Tarquinio habría sido enviado a Colacia para llevar a cabo varias gestiones en mitad de la guerra ${ }^{36}$. Durante su estancia en esa ciudad se habría alojado en casa de su pariente Colatino ${ }^{37}$, pues sabiendo que se encontraba combatiendo en Ardea, habría aprovechado para intentar satisfacer su atracción por su esposa Lucrecia ${ }^{38}$.

A este respecto la narración de Dionisio de Halicarnaso se asemeja sobremanera al relato expuesto por Livio, pues destaca que Sexto Tarquinio habría esperado hasta la noche para deslizarse hasta los aposentos de Lucrecia ${ }^{39}$, donde blandiendo una espada habría amenazado a la joven ${ }^{40}$, ofreciéndole dos alternativas: 0 bien acceder a mantener relaciones de manera voluntaria $\mathrm{y}$, de esa forma, ganarse el favor del heredero al trono ${ }^{41} \mathrm{o}$, en caso de rechazar esa proposición, morir sabiendo que sufriría la terrible deshonra de que su cuerpo fuese descubierto junto al cadáver de uno de sus esclavos en su lecho, como si hubieran sido descubiertos cometiendo adulterio ${ }^{42}$.

Al igual que en la narración de Livio, en la obra de Dionisio de Halicarnaso se incide en la firme resistencia que habría opuesto Lucrecia ante esas graves amenazas, destacando que Sexto Tarquinio tuvo que repetir insistentemente sus amenazas a la joven, hasta que finalmente, obligada en última instancia a decidirse entre esas dos alternativas, Lucrecia habría optado por acceder a las peticiones del hijo del monarca ante el temor a las consecuencias que conllevaría una muerte de carácter tan infamante.

Sin embargo, a partir de ese momento, la narración de Dionisio de Halicarnaso se despega por completo del relato de la obra de Livio, pues mientras que este afirmaba que la joven había enviado múltiples mensajeros para que tanto su marido como su padre, acompañados de sendos amigos de confianza, acudieran prestos en su auxilio a Colacia, según Dionisio de Halicarnaso habría sido la propia Lucrecia quien se habría desplazado vestida de negro, con los ojos llenos de lágrimas, sin detenerse un instante durante el viaje hasta llegar a su hogar familiar en Roma.

inventado en el siglo III a.C. por el historiador Fabio Pictor y quienes creen que esta leyenda se habría conformado a lo largo del siglo IV a.C. sobre la base de diversos relatos religiosos procedentes de Ardea.

${ }^{35}$ Dion. Hal., Ant. Rom. 4.64.1.

${ }^{36}$ Dion. Hal., Ant. Rom. 4.64.2.

${ }^{37}$ Dion. Hal., Ant. Rom. 4.64.3.

${ }^{38}$ Dion. Hal., Ant. Rom. 4.64.4.

${ }^{39}$ Dion. Hal., Ant. Rom. 4.64.5.

${ }^{40}$ Dion. Hal., Ant. Rom. 4.65.1.

${ }^{41}$ Dion. Hal., Ant. Rom. 4.65.2.

${ }^{42}$ Dion. Hal., Ant. Rom. 4.65.3. 


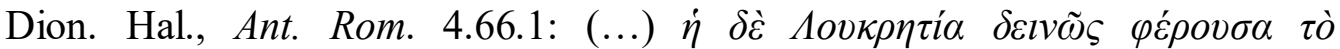

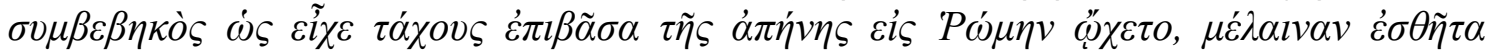

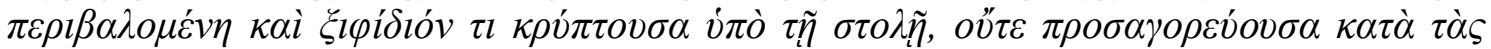

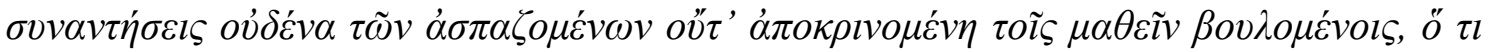

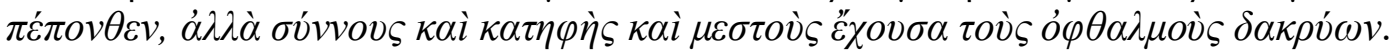

De acuerdo con este último testimonio, la joven habría sido recibida en su casa tanto por su padre como por varios parientes, que, perplejos ante su estado de alteración, le habrían pedido que explicase los motivos de su desventura. Ante esa petición, Lucrecia habría rogado a su padre que convocase a cuantos amigos y parientes fuese posible para que todos pudieran escuchar de su propia boca los ultrajes de los que había sido víctima durante la noche anterior y actuasen en consecuencia.

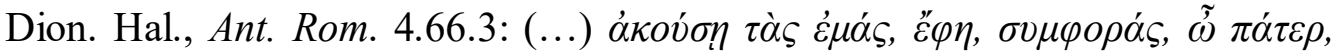

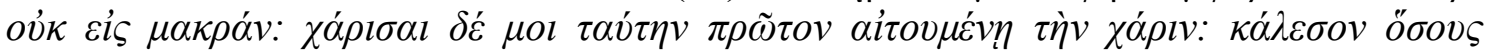

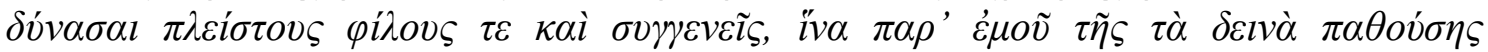

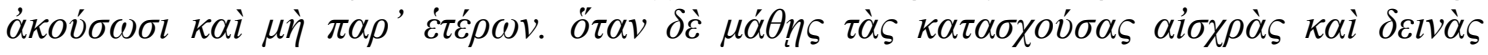

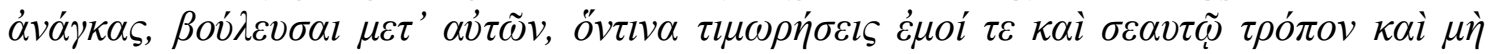

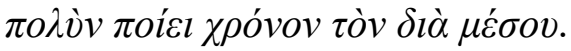

Como se puede observar en este punto del relato existen notables divergencias con respecto a la versión expuesta por Livio. A diferencia de lo que este último sostenía, según Dionisio de Halicarnaso la reunión de los amigos y familiares de Lucrecia no habría sido convocada por la joven en Colacia, sino que esta se habría desplazado hasta Roma para solicitar a su padre que convocase en su casa a sus familiares y amigos ${ }^{43}$, entre los que, además, es preciso destacar que no se encontraba su marido Colatino, constatación que, como tendremos ocasión de analizar más adelante, puede ser un indicio en favor de una posible intervención de un consilium domesticum en este episodio.

Ahora bien, posiblemente la diferencia más relevante a nuestros efectos radique en la funcionalidad que esta congregación doméstica presenta en el curso de la narración. Y es que si bien es cierto que tanto Tito Livio como Dionisio de Halicarnaso insisten en destacar que Lucrecia habría empleado esa reunión para informar de los hechos acaecidos durante la noche anterior, pedir venganza en su nombre y dar testimonio de su muerte, parece que la presencia de sus familiares y amigos en ese momento tan crucial desempeña un papel muy distinto en cada uno de los dos relatos expuestos.

Mientras que en la narración de Livio resulta indispensable que la joven Lucrecia se reúna con sus allegados para comunicar la ofensa recibida a manos del hijo del rey y, que, de un modo casi literario ${ }^{44}$, funcione como desencadenante de la reacción

\footnotetext{
${ }^{43}$ Esta posibilidad solo se habría reconocido a los varones, pues como manifiesta M. J. BRAVO BOSCH, El iudicium domesticum, op. cit., p. 142: "Lucrecia, al carecer de patria potestas, no estaría legitimada para convocar el iudicium domesticum, potestad reservada única y exclusivamente al paterfamilias, por lo que la convocatoria efectuada por una mujer sería nula de pleno derecho, o inexistente desde el principio por cuanto no es el sujeto activo legitimado para la convocatoria de un tribunal familiar".

${ }^{44}$ Como sucede con muchas de las narraciones de origen legendario recogidas en la magna obra de Livio, la representación final del episodio de Lucrecia presenta elementos propios de la cultura helenística, hasta el punto de que A. GUARINO, Il dossier di Lucrezia, op. cit., p. 215 nt. 38 ha puesto de manifiesto que
} 
popular contra la familia real, en el relato de Dionisio de Halicarnaso no parece que esa reunión constituya un simple nexo de unión entre ambos episodios históricos, sino que más bien parece presentarse como un fin en sí mismo. De acuerdo con el testimonio de este autor, Lucrecia no comunica su violación nada más llegar a casa de su padre, sino que ruega a su padre que convoque a los familiares y amigos de su familia, y solo cuando todos estos se encuentran presentes procede entonces a relatar los abusos de los que ha sido víctima y ruega que se promueva la venganza contra su agresor.

Dado que nada hubiera cambiado en la correlación de los sucesos relatados por Dionisio de Halicarnaso si la joven se hubiera limitado a contar su desgraciada vivencia ante su padre y el resto de familiares que lo acompañaban cuando se presentó en su casa, no cabe sino interpretar que la petición de que se convocase a los familiares y a los amigos de la comunidad familiar de Lucrecia es una acción que, más allá de que pudiera servir para otorgar una mayor publicidad a la ofensa sufrida por esta joven, habría constituido un acto necesario a la vista de los hechos acontecidos.

Desde esa misma perspectiva resulta razonable que Valerio Maximo, que sin duda habría tenido acceso a esta narración acerca de la muerte de Lucrecia, concluyese que en este episodio histórico se habría producido la intervención de un consilium domesticum, que como hemos señalado en el primer apartado de este capítulo, el propio autor habría calificado como "concilium neccesarium" precisamente porque consideraba que se habría tratado de una convocatoria de carácter ineludible.

Esta constatación nos lleva a plantearnos cuáles podrían haber sido los motivos por los que Lucrecia, al menos en el relato de Dionisio de Halicarnaso, muestra ese inusitado interés porque su padre convoque a cuantos familiares y amigos pueda para transmitirles de primera mano su fatal experiencia, rogar venganza por esos hechos y proceder a quitarse la vida en su presencia. Responder a esta cuestión implica necesariamente adentrarse tanto en la calificación jurídica de los hechos en los que se habría visto envuelta Lucrecia como en las posibles sanciones que se habrían aplicado a las personas involucradas en los mismos durante la época arcaica.

\section{SOBRE LA SANCIÓN DEL ADULTERIO EN LA ÉPOCA ANTIGUA}

Las distintas narraciones que se han conservado sobre este episodio coinciden en remarcar que, independientemente del abominable comportamiento de Sexto Tarquinio, lo cierto es que, de acuerdo con la arcaica mentalidad romana, habría existido una cierta voluntariedad por parte de la víctima. A pesar de que en todo momento actuara movida por el miedo a una muerte deshonrosa, en última instancia, Lucrecia habría accedido a satisfacer los deseos de su agresor motu propio. Y esa circunstancia habría propiciado que si bien su comunidad familiar estaría legitimada para acudir a la venganza privada ${ }^{45}$, la joven hubiera incurrido en un delito de adulterio.

\footnotetext{
"l'azione escogitata da Livio permette al dramma di concludersi in presenza di tutti i suoi personaggi, secondo i canoni classici della tragedia greca".

${ }^{45}$ Como ha señalado B. SANTALUCIA, Diritto e proceso penale nell'antica Roma, Milán, Giuffrè, 1989, p. 6 ss., en la antigua Roma se aceptaba que, ante la ausencia de una tipificación exhaustiva de ciertos actos, las actuaciones antijurídicas se resolvieran a través de un sistema de venganza privada que era ejecutado por los miembros de la comunidad familiar de la víctima.
} 
El adulterio constituía un delito imputable exclusivamente a las mujeres casadas que mantenían relaciones sexuales con otro hombre que no fuera su propio marido ${ }^{46}$. Durante la época arcaica la comisión de este delito se evaluaba de una manera objetiva, es decir, no se tenía en cuenta que hubiera mediado algún tipo de intimidación o violencia para doblegar la voluntad de la mujer ${ }^{47}$, sino únicamente que esta hubiera accedido o no a mantener esas relaciones extraconyugales.

Esa conducta suponía un gravísimo atentado contra las virtudes, en especial contra la pudicitia que debía preservar una mujer virtuosa en la antigua Roma. Con la comisión de un acto de adulterio infringía gravemente su deber de procurar herederos legítimos que asegurasen la continuidad de la familia en el tiempo. Al mantener relaciones con otros hombres distintos a su marido se perdía cualquier certidumbre en torno a la procedencia de los descendientes y, en consecuencia, la estirpe familiar quedaba irremediablemente contaminada por elementos extraños al grupo familiar ${ }^{48}$.

Debido a las fatídicas consecuencias que un acto de adulterio conllevaba para una antigua familia romana, desde tiempos remotos se habría establecido toda una ordenación jurídica especialmente severa para sancionar ese tipo de malas conductas. A este respecto, en un fragmento procedente de la obra de Dionisio de Halicarnaso se recuerda que una lex emitida por Rómulo establecía la posibilidad de que el marido pudiera dar muerte a su esposa cuando esta hubiera sido descubierta cometiendo adulterio o bebiendo vino, pues en esa época se consideraba que el estado de embriaguez incitaba a las mujeres a cometer actos impúdicos ${ }^{49} \mathrm{y}$, por tanto, la ingesta de vino podía conducir a que una mujer casada terminase incurriendo en actos de adulterio.

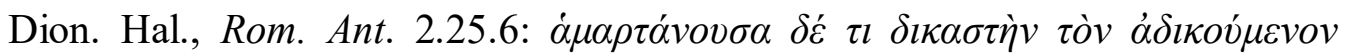

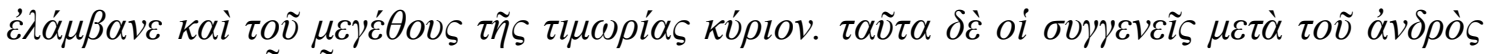

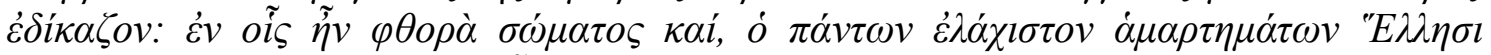

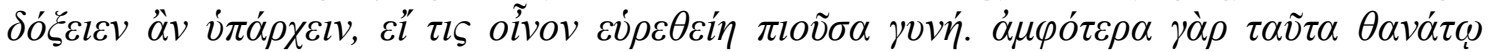

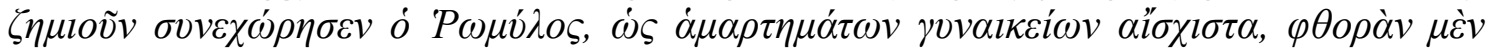

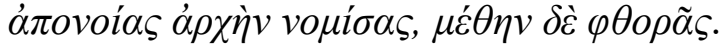

A pesar de la valiosa información que contiene este fragmento, nuestra atención debe centrarse de manera especial en el hecho de que estas sanciones eran aplicadas por el marido acompañado por un conjunto de parientes ${ }^{50}$. Dionisio de

\footnotetext{
${ }^{46}$ C. FAYER, La familia romana, vol. III, Roma, 2005, p. 190, señala que: "per il diritto romano solo la donna violava la fedeltà congiugale e si rendeva colpevole di adulterio, mentre, se il marito aveva relazioni extramatrimoniali, purché non con donne sposate o ingenuae et honestae, non cometteva adulterio".

${ }^{47}$ A este respecto, M. J. BRAVO BOSCH, El iudicium domesticum, op. cit., p. 97 ha puesto de manifiesto que este episodio "bien podría considerarse como remoto antecedente de la actio quod metus causa, acción pretoria introducida hacia el año 80 a.C. por el pretor Octavio - de ahí el nombre de formula octaviana - para proteger a la víctima de un acto de violencia o metus".

${ }^{48}$ En las fuentes se emplean formas verbales como "polluere" (Sen., contr. 4 exc. 7; CI 9.9 .12 (a. 239)) o "corrompere" (Tryphon., 1 disp., D. 50.16.225) para referirse a la pretendida contaminación de la sangre que se derivaba de un acto de adulterio cometido por una mujer casada.

${ }^{49}$ C. FAYER, La familia romana III, op. cit., p. 196 nt. 24 recoge un elenco de fuentes de diversas épocas en las que se reprocha la ingesta de vino por parte de las mujeres romanas.

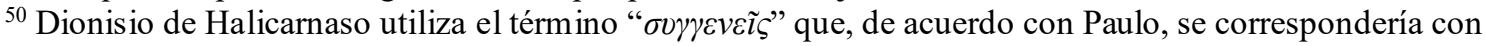
la noción latina de parientes cognados: Nomen cognationis a graeca voce dictum videtur: suggeneis enim illi vocant, quos nos cognatos appellamus (Paul., l.s. de grad. et adfin., D. 38.10.10.1).
} 
Halicarnaso no aclara si se trataba de un órgano jurisdiccional facultado para enjuiciar los hechos acontecidos y, en su caso, aplicar la correspondiente sanción a la mujer que había cometido adulterio o, como parece más probable, ese consilium domesticum constituía un órgano consultivo, cuyos veredictos quedaban en última instancia sometidos a la voluntad del pater familias, que, en virtud de su patria potestas ${ }^{51}$, podía sancionar o no esos hechos.

Con el fin de arrojar algo de luz a este respecto cabe ahora traer a colación otro fragmento extraído de la obra de Aulo Gelio en el que se reproduce un discurso senatorial de Marco Porcio Catón el Viejo. De acuerdo con las palabras atribuidas al viejo censor, mientras que la mujer no estaba facultada para actuar contra su marido infiel, en su época se habría reconocido a los maridos la potestad de proceder inmediatamente a la ejecución de sus esposas si estas hubieran sido descubiertas en flagrante adulterio ${ }^{52}$.

Gell., Noct. Att. 10.23.5: De iure autem occidendi ita scriptum: "In adulterio uxorem tuam si prehendisses, sine iudicio inpune necares; illa te, si adulterares sive tu adulterarere, digito non auderet contingere, neque ius est".

La utilización de la expresión "sine iudicio" en este fragmento parece hacer referencia a que en estos casos no habría sido necesario que el marido convocase a ningún otro pariente o conocido para determinar la culpabilidad de su esposa ${ }^{53}$. De esta manera, es posible aventurar que tradicionalmente se habrían distinguido dos formas de resolver los supuestos de adulterio: mientras que, por un lado, se admitía que se pudiera ejecutar a la mujer casada descubierta cometiendo un acto de adulterio sin necesidad de realizar más indagaciones en el asunto, si se sospechaba de la comisión de un acto de adulterio, pero no se había producido de manera flagrante, había que proceder a la constitución de una especie de consilium domesticum para esclarecer los hechos acaecidos y, en su caso, aplicar la sanción correspondiente a esa mujer ${ }^{54}$. Sin embargo,

\footnotetext{
${ }^{51}$ Esta es la interpretación sostenida por E. VOLTERRA, Il pretteso tribunale domestico, op. cit., p. 107, quien mantenía que "nei numerosi esempi fornitici dai testi letterari e giuridici, nei quali il paterfamilias giudica il sottoposto alla patria potestà e lo colpisce con una sanzione, non ne troviamo uno solo in cui l'atto del pater possa apparire come espressione di un potere diverso dalla patria potestas o come estrinsecazione di una volontà estranea e superiore alla sua. La valutazione dell'atto compiuto dal sottoposto dipende esclusivamente dall'arbitrio del pater: mai essa risulta diretta all'accertamento e all'applicazione di una norma giuridica che s'imponga al pater: non esistono criterio uniformi di valutazione nè uniformità di sanzioni”.

${ }^{52}$ En relación con este pasaje concreto, G. RIZELLI, «"Stuprum" e "adulterium" nella cultura augustea e la "lex Iulia de adulteriis"», en BIDR 29, 1987, p. 370 nt. 63 ha remarcado que la distinción de las sanciones aplicadas en caso de que el acto de adulterio fuese cometido por un hombre o una mujer estaría relacionado con que el verbo "adulterare" se emplee tanto en forma activa como pasiva. De acuerdo con este autor, la primera de las utilizaciones denotaría que el hombre toma la iniciativa de seducir a la mujer, mientras que en el segundo caso sería la mujer quien seduce al hombre.

${ }^{53}$ P. VOCI, «Storia della patria potestas da Augusto a Diocleziano», en SDHI 51, 1985, p. 55, ha recalcado que la expresión "sine iudicio" empleado por Aulo Gelio en este fragmento solo puede entenderse referida al consilium domesticum, pues en estos casos el marido solo habría tenido dos posibilidades de actuación: o mataba a su esposa adúltera o convocaba al consejo doméstico para evaluar los hechos.

${ }^{54}$ A partir de un fragmento procedente de la obra de Plutarco en el que se afirma que en tiempos de Rómulo se habría permitido que cualquier marido pudiera repudiar a su esposa si esta hubiera cometido adulterio o se hubiera emborrachado (Plut., Rom. 22.3), R. ASTOLFI, «Aspetti del diritto matrimoniale in età arcaica», en $S D H I 58,1992$, p. 258 ss. ha sostenido que es muy posible que la condena a muerte por cometer adulterio fuese sustituida durante la época antigua por la posibilidad de repudiar a la mujer.
} 
este fragmento no aporta más información ni sobre la composición de ese consilium domesticum, ni tampoco aclara quien sería la persona encargada de convocar esa reunión, escuchar a los intervinientes y, en su caso, imponer la sanción correspondiente sobre la mujer adúltera.

Aunque tanto el fragmento recabado de la obra de Dionisio de Halicarnaso como el pasaje de Aulo Gelio que alude al discurso catoniano reconocen la facultad del marido de dar muerte a su mujer en caso de haber sido descubierta cometiendo flagrante adulterio, eso no quiere decir que necesariamente tuviera que ser el propio marido quien, envestido de la patria potestas que le confería su matrimonio cum manu ${ }^{55}$, se encargase de convocar un consilium domesticum en caso de que se acusase a su esposa de un acto de adulterio en el que no hubiera mediado flagrancia. De hecho, esa ordenación no termina de casar adecuadamente con el sentido de justicia de los antiguos romanos.

En este sentido, no parece equitativo que la inocencia o culpabilidad de la mujer que había sido acusada de adulterio dependiese del examen de un consilium domesticum compuesto por los familiares y amigos de un marido que había sido gravemente ofendido por esos mismos hechos enjuiciados. Por ese motivo, resulta más razonable suponer que los miembros que componían ese consilium domesticum fuesen los parientes agnados de la propia mujer acusada de adulterio ${ }^{56}$, pues con su intervención se habría garantizado una cierta imparcialidad en este proceso de acusación.

A la vista de toda la información recabada en relación con la originaria regulación de los supuestos de adulterio en la antigua Roma, creemos que estamos en condiciones de arrojar algo más de luz acerca de la posible intervención de un consilium domesticum en el legendario episodio de la muerte de Lucrecia.

\section{A MODO DE CONCLUSIÓN}

Como hemos puesto de manifiesto en el apartado anterior, todo parece indicar que en los primeros compases de la historia jurídica romana se habrían contemplado dos vías de resolución de los casos de adulterio en función de que mediase o no flagrancia. Mientras que, de acuerdo con el testimonio de Dionisio de Halicarnaso, el marido que descubriese a su mujer cometiendo adulterio podía proceder directamente a su ejecución sin necesidad de realizar ningún otro trámite previo, Aulo Gelio parece dar a entender que habría sido necesario llevar a cabo una cierta evaluación de los hechos por parte de un consilium domesticum si se trataba de un caso no flagrante. Ambas posibilidades parecen encontrarse presentes en el relato de la muerte de Lucrecia.

\footnotetext{
${ }^{55}$ La mayor parte de la doctrina romanística moderna considera que el origen del matrimonio sine manu se habría producido a partir de la práctica del trinoctium, aunque no habría adquirido categoría jurídica propia hasta finales del siglo III a.C. Sobre esta cuestión, vid. L. PEPPE, Posizione giuridica e ruolo sociale della donna romana in età republicana, Milán, 1984, p. 107 ss.

${ }^{56}$ Una recopilación de las distintas posiciones doctrinales que se han planteado sobre esta cuestión se encuentra en C. FAYER, La familia romana III, op. cit., p. 199 nn. 30-32, donde la autora distingue entre aquellos autores que defienden la constitución de un consilium domesticum compuesto exclusivamente por parientes de la mujer, otros que afirman que se trataba de parientes del marido y, por último, aquellos que sostienen que intervenían parientes tanto de la mujer como del marido.
} 
La primera manifestación acerca de la posible aplicación de la ordenación que sancionaba los casos de adulterio se aprecia en la actuación de Sexto Tarquinio. Como recuerdan todas las fuentes que hemos analizado a lo largo del presente trabajo, el hijo del rey habría tratado de satisfacer sus deseos optando, en primer lugar, por confesar su amor hacia Lucrecia, pero tras observar que con su declaración no obtenía los resultados esperados, habría amenazado a la joven con la muerte $\mathrm{y}$, ante la resistencia que esta seguía oponiendo, habría terminado por doblegar la voluntad de Lucrecia con la amenaza de que no solo perdería la vida, sino que además el propio Sexto Tarquinio se encargaría de asesinar a un esclavo y colocar su cadáver en su lecho para alegar al día siguiente que había dado muerte a ambos al encontrarlos cometiendo adulterio.

Esta última amenaza sí que habría surtido efecto porque ambos protagonistas eran plenamente conscientes de la regulación vigente en relación con el adulterio. Tanto Sexto Tarquinio como Lucrecia sabían que en virtud a la ley aprobada en tiempos de Rómulo se podía dar muerte a la mujer que hubiese sido descubierta cometiendo adulterio. Y aunque parece que esta potestad se habría atribuido exclusivamente al marido de la mujer adúltera, es posible que antiguamente se hubiera admitido que, dado que los casos de adulterio afectaban a toda la esfera familiar, esta posibilidad se extendiese a sus parientes. A este respecto, cabe recordar que Sexto Tarquinio estaba emparentado con Colatino ${ }^{57}$ y, por lo tanto, su amenaza habría resultado perfectamente verosímil ${ }^{58}$.

De esta forma, apoyándose en la ordenación jurídica de la época, Sexto Tarquinio habría situado a Lucrecia entre la espada y la pared. La joven se habría visto abocada a elegir ente acceder a mantener relaciones con un hombre que no era su marido o morir en unas circunstancias tan deshonrosas que no solo se extenderían sobre su recuerdo, sino que afectarían por completo al honor de su propia familia. Ante esta terrible disyuntiva, Lucrecia habría sopesado las consecuencias que suponían cada una de estas alternativas y finalmente se habría decidido por la que consideraba el mal menor.

No sabemos si la joven habría sido consciente en ese momento de que su destino estaba completamente escrito, pues lo cierto es que, aunque hubiera mediado intimidación por parte de su agresor, conforme a la antigua ordenación jurídica romana se consideraba que, en último término, Lucrecia había accedido a mantener relaciones con un hombre que no era su marido y, por tanto, había cometido adulterio. Aunque en el relato de Livio se aduce que su propio marido habría intentado convencerla de que no se pecaba con el cuerpo, sino con la mente ${ }^{59}$, en esa época resulta inimaginable que se pudiera contemplar la intimidación como eximente en un acto de adulterio ${ }^{60}$.

$\mathrm{Y}$ en este punto entra en juego la segunda variante que contemplaba la antigua ordenación jurídica romana en relación con el adulterio, pues la conducta de Lucrecia habría constituido un caso de adulterio no flagrante. Tal y como hemos señalado que

\footnotetext{
${ }^{57}$ Cfr. Dion. Hal., Ant. Rom. 4.64.2.

${ }^{58}$ A. WATSON, Rome of the XII Tables: Persons and Property, Nueva Jersey, 1975, p. 36.

${ }^{59}$ Vid supra Liv. 1.58: "mentem peccare, non corpus".

${ }^{60}$ Como hemos apuntado anteriormente, hasta la introducción de la denominada actio quod metus causa en torno al año 80 a.C. no se habrían considerado inválidos los actos concluidos en virtud de la intimidación. En relación con este recurso procesal y sus efectos jurídicos, vid. E. CALORE, “Actio quod metus causa". Tutela della vittima e azione in rem scripta, Milán, Giuffré, 2011.
} 
parece deducirse de un fragmento de la obra de Aulo Gelio, en estos casos no podía procederse inmediatamente con la ejecución de la mujer adúltera, sino que resultaba indispensable que se llevase a cabo una cierta evaluación de los hechos por parte de un consilium domesticum conformado por los familiares y amigos más cercanos de la familia de la mujer que se hubiera visto involucrada en esos hechos.

$\mathrm{Y}$ esto es precisamente lo que sucede en este caso, pues en todos los testimonios que se han conservado sobre la muerte de Lucrecia se incide en que la joven se quita la vida en presencia de sus familiares y amigos, es decir, en lo que Valerio Máximo califica como un "consilium necesorium" 61.

Una vez se ha constatado que en este episodio histórico habrían concurrido las circunstancias que el antiguo ordenamiento jurídico romano requería para convocar un consilium domesticum, nos encontramos en condiciones de interpretar cómo podrían haberse desarrollado los hechos previos a la muerte de la joven Lucrecia. En este sentido, resulta más razonable suponer que los hechos se sucedieran de una forma más ajustada a cómo se describe en la obra de Dionisio de Halicarnaso que al relato que recoge Livio. Incluso aceptando que la iniciativa hubiera partido de Lucrecia, no resulta verosímil que ella misma hubiera podido convocar a los parientes, amigos y conocidos de su familia, pues como señalamos anteriormente, la facultad de convocar un consilium domesticum correspondía exclusivamente a un pater familias.

En este caso esa potestad habría correspondido a su padre, quien habría procedido a convocar a parientes, amigos y allegados de la familia de la mujer acusada de adulterio, aunque es posible que también hubiera invitado a su marido Colatino para que estuviera presente en esa fatídica reunión. En todo caso, parece evidente que en ese consilium se habría constatado que los hechos relatados por Lucrecia constituían un caso de adulterio y, en consecuencia, debían ser castigados severamente.

El resultado alcanzado en el seno de ese consilium domesticum concuerda con lo que la joven Lucrecia posiblemente conocía desde la noche anterior: independientemente de que hubiera demostrado una admirable resistencia ante el depravado Sexto Tarquinio, finalmente había accedido, aunque fuese movida por el temor a una muerte deshonrosa, a mantener relaciones sexuales con un hombre distinto a su marido. Esa conducta no solo suponía una deshonra para su propio marido, sino que también mancillaba a su familia y, por encima de todo, comportaba que a partir de ese momento su vida como mater familias carecía de cualquier sentido, pues ya nunca podría cumplir con su deber de proporcionar una descendencia legítima que perpetuase la estirpe de su familia. Ante esa perspectiva la joven decide quitarse la vida para, de ese modo, al menos reparar en parte la deshonra que sus actos habían supuesto para ella misma y sus familiares ${ }^{62}$.

\footnotetext{
${ }^{61}$ Vid. supra Val. Max., fact. et dict. mem. 6.1.1.

${ }^{62}$ P. D. CONESA NAVARRO y R. GONZÁLEZ FERNÁNDEZ, «Honesta Mors. Suicidas y muertes inducidas de mujeres de la antigua Roma», en Mujeres en tiempos de Augusto: realidad social e imposición legal (coord. M. J. BRAVO BOSCH), Valencia, 2016, p. 587 señalan que con esa actuación se pretendía "borrar cualquier atisbo de infamia o deshonra para la propia causante y también para su familia. Sin temor a equivocarnos podemos situar el honor como el eje dominante de este tipo de romana mors. Una suerte de honesta mors. Una muerte virtuosa que embelleciera una vida deshonrada. Una muerte honesta por la eficacia de aquello que es honesto, es decir, de la virtud y del alma que menosprecia los bienes eternos o simplemente una muerte honrosa preferible a una vida infame".
} 
Ahora bien, más allá del dramatismo que entraña este último acto protagonizado por la joven Lucrecia ${ }^{63}$, a nuestro juicio resulta especialmente reseñable la importancia que presenta la intervención del consilium domesticum en el desenlace de esta historia. Aunque tradicionalmente la atención se ha desviado hacia otros aspectos, lo cierto es que en todos los relatos que se han conservado sobre este episodio legendario se incide en que la joven habría esperado a que estuviesen reunidos sus familiares y amigos para contarles todo lo sucedido la noche anterior $y$, solo posteriormente, quitarse la vida.

Si bien es cierto que las fuentes antiguas presentan este desarrollo de los hechos como una sucesión lógica para que Lucrecia pueda contar su desventura y, de esa forma, desencadenar la reacción popular que terminará con el derrocamiento de la monarquía, tampoco puede obviarse que para obtener ese mismo resultado no resultaba indispensable promover ninguna reunión de esas características. En este sentido, nada habría cambiado si la joven hubiera relatado esos hechos por escrito en los mensajes que, según Livio ${ }^{64}$, habría dirigido a su padre y a su marido para que acudieran hasta Colacia en su auxilio o si hubiera relatado su desventura directamente ante su padre y el resto de familiares que, según Dionisio de Halicarnaso ${ }^{65}$, se encontraban en su casa de Roma cuando Lucrecia llegó absolutamente desconsolada desde Colacia.

Sin embargo, la intervención de ese consilium domesticum se encuentra presente en todos los relatos que se han conservado, lo que nos lleva a pensar que a pesar de que los autores antiguos tan solo le otorgasen una relativa importancia como nexo de unión entre la violación sufrida por Lucrecia y la caída de la monarquía romana, es muy posible que, en realidad, ostentase un papel mucho más determinante en este episodio histórico: no es descabellado pensar que la joven Lucrecia acudiese en busca de apoyo a su familia y que solo cuando constatase que, en virtud del veredicto de ese consilium domesticum, sus actos habían constituido un acto de adulterio, decidiese entonces quitarse la vida para salvaguardar su memoria y el honor de su propia familia.

Desgraciadamente no ha quedado constancia sobre si este consilium domesticum se habría limitado a confirmar que los sucesos relatados por Lucrecia eran constitutivos de un acto de adulterio o incluso había llegado a recomendar una sanción para la joven. Ahora bien, no cabe duda de que la única solución razonable a los ojos de la primitiva sociedad romana pasaba por la muerte de la joven y, por ese motivo, hubiera o no mediado la emisión de una condena previa por parte de su pater familias, Lucrecia habría optado por quitarse a sí misma la vida asumiendo así su destino.

De esta manera, la muerte de Lucrecia no solo sería el primer episodio histórico en el que se tiene constancia de la intervención de un consilium domesticum, sino que además ofrece una valiosa información sobre la forma de funcionamiento de un órgano que tan solo intervenía en casos de especial gravedad en los que se hubiera visto inmerso un miembro del grupo familiar en cuestión y que, como se puede

\footnotetext{
${ }^{63}$ A. GUARINO, Il dossier di Lucrezia, op. cit., p. 216 ss. afirmaba que mientras el segundo acto del drama de Lucrecia resultaba perfectamente verosímil desde un punto de vista histórico, el tercer acto es resultado de una reconstrucción posterior que aúnaba elementos propios de la tragedia griega con otros inverosímiles como "in quella scena di Lucrezia che, ferma, annuncia di volersi uccidere e dei suoi congiunti che, in grupo immobile di fronte a lei (o, più precisamente, al pubblico), tentano di dissuaderla, senza menormente impedirle un'azione, su cui Livio conta come conclussione suprema del dramma".

${ }^{64}$ Vid. supra Liv. 1.58.

${ }^{65}$ Vid. supra Dion. Hal., Ant. Rom. 4.66.1.
} 
corroborar en este caso, resultaba determinante para establecer la posición final del grupo doméstico en relación con los hechos que se sometían a su enjuiciamiento: la joven Lucrecia no se quita la vida porque considere que ha cometido una acción imperdonable, sino como consecuencia de la valoración que su consilium domesticum realiza de esos hechos.

\section{BIBLIOGRAFÍA}

APPLETON, C.: «Trois épisodes de l'histoire ancienne de Rome: les Sabines, Lucrèce, Virginie», en $R H, 4.3,1924$, pp. 193-271.

ASTOLFI, R.: «Aspetti del diritto matrimoniale in età arcaica», en SDHI 58, 1992, pp. 230-261.

BALDUCCI, A.: «Intorno al iudicium domesticum», en Archivio Giuridico Filippo Serafini, 191, 1976, pp. 69-97.

BANKSTON, C. L.: «Marcus Junius Brutus», en Great Lives from History: Notorious Lives, Salem Press, 2007, pp. 146-148.

BONFANTE, P.: Corso di diritto romano I, Roma, 1925.

BRAVO BOSCH, M. J.: «El iudicium domesticum», en Revista General de Derecho Romano, 17, 2011.

CALORE, E.: "Actio quod metus causa". Tutela della vittima e azione in rem scripta, Milán, Giuffré, 2011.

CANTARELLA, E.: Dammi mille baci. Veri uomini e vere donne nell'antica Roma, Milán, 2016.

CONESA NAVARRO P. D. y GONZÁLEZ FERNÁNDEZ, R.: «Honesta Mors.

Suicidas y muertes inducidas de mujeres de la antigua Roma», en Mujeres en tiempos de Augusto: realidad social e imposición legal (coord. M. J. BRAVO BOSCH), Valencia, 2016, pp. 585-611.

DE MARTINO, F.: Storia della Costituzione romana, vol. I, Jovene, Nápoles, 1972.

DE SANCTIS, G.: Storia dei Romani, vol. IV.2, Florencia, 1958.

DONADIO, N.: «Iudicium domesticum, riprovazione sociale e persecuzione publica di atti commessi da sottoposti alla patria potestas», en Index, 40, 2012, pp. 175-195.

DONALDSON, I.: The Rapes of Lucretia: A Mith and its Transformations, Nueva York, 1982.

DÜLL, R.: «Iudicium domesticum, abdicatio und apokeryxis», en ZSS, 63, 1943, pp. 54 ss.

FAYER, C.: La familia romana, vol. I, Roma, 1994.

GROH, V.: «La cacciata dei re romani. Analisi letteraria e storica», en Athenaeum, 6, 1928, pp. 289-324. 
GROSSO, G.: «L'esame di coscienza di uno storico e i problema del più antico sviluppo costituzionale romano», en RISG, 2, 1948, pp. 123 ss.

GUARINO, A.: «Il dossier di Lucrezia», en Labeo 5, 1959, pp. 211-216.

KASER, M.: Das römische Privatrecht, vol. I, Múnich, 1971.

KUNKEL, W.: «Das Konsilium im Hausgericht» en ZSS, 83, 1966, pp. 219-251.

LE BOHEC, Y., LE GLAY, M., y VOISIN, J. L.: A History of Rome, Wiley-Blackwell, 2009.

MALASKOV, G.: «Valerius Maximus and Roman Historiography. A Study of the exempla Tradition», en $A N R W$ II, 32 (1), pp. 437-496.

MASTROCINQUE, A.: «La cacciata di Tarquinio il Superbo: tradizione romana e letteratura greca», en Athenaeum, 62, 1984, pp. 210-229.

MOMMSEN, T.: Römisches Strafrecht, Leipzig, 1899.

MONTERO HERRERO, S.: «Gabii a través del foedus gabinum», en Cuadernos de trabajos de la Escuela Española de Historia y Arqueología en Roma, 15, 1981, pp. 916.

OGILVIE, R. M.: A Commentary on Livy. Books 1-5, Oxford, 1965.

PEPPE, L.: Posizione giuridica e ruolo sociale della donna romana in età republicana, Milán, 1984.

POLAY, E.: «Das "regimen morum" des Zensors und die sogenannte Hausgerichtsbarkeit», en Studi in onore di Edoardo Volterra III, Milán, 1971, pp. 263317.

RIZELLI, G.: "In has servandae integritatis custodias nulla libido inrumpet (Sen., contr. 2.7.3). Donne, passioni, violenza», en Violenza sessuale e società antiche. Profili storico-giuridici, pp. 149-199.

- $\quad$ «"Stuprum" e "adulterium" nella cultura augustea e la "lex Iulia de adulteriis"», en BIDR 29, 1987, pp. 355-388.

RÖMER, F.: «Zum Aufbau der Exemplasammlung des Valerius Maximus», en WS 103, 1990, pp. 99-107.

RUGGIERO, A.: «Nuove riflessioni in tema di tribunale domestico», en Sodalitas.

Scritti in onore di A. Guarino, 4, 1984, pp. 1593-1600.

RUSSO RUGGERI, C.: «Ancora in tema di iudicium domesticum», en Iuris Antiqui Historia, 2010, pp. 51-102.

SALAZAR REVUELTA, M.: «Estatus jurídico y social de la materfamilias en el marco de la ciudadanía romana», en Mulier: algunas historias e instituciones de Derecho Romano, Dykinson, 2013, pp. 199-224.

SCHWEGLER, A.: Römische Geschichte, vol. I.2, Tubinga, 1853.

SANTALUCIA, B.: Diritto e proceso penale nell'antica Roma, Milán, Giuffrè, 1989. 
VOCI, P.: «Storia della patria potestas da Augusto a Diocleziano», en SDHI 51, 1985 , pp. 1-68.

VOLTERRA, E.: «Il pretteso tribunale domestico in diritto romano», en RISG, 85, 1948, pp. 103-153.

WATSON, A.: Rome of the XII Tables: Persons and Property, Nueva Jersey, 1975.

WESENER, G.: «Iudicium domesticum», en Realenzyklopädie der klassischen Altertumwissenschaft, Suppl. 9, 1962., p. 374.

WISEMAN, T. P.: «Roman Republic, year one», en Greece \& Rome, 45.1, 1998, pp. 19-26. 